\title{
An alteration of the subcommissural organ (SCO) leads to aqueductal stenosis and hydrocephalus Karin Vío ${ }^{1}$, Carolina Wagner ${ }^{1}$, Sara Rodrìguez ${ }^{1}$, Federico Bátiz ${ }^{1}$, Antonio J Jiménez ${ }^{2}$, José Manuel Pérez-Fígares ${ }^{2}$ and Esteban M Rodríguez*1
}

\author{
Address: ${ }^{1}$ Instituto de Histología y Patología, Universidad Austral de Chile, Valdivia, Chile and ${ }^{2}$ Departamento de Biología Celular, Universidad \\ de Málaga, España \\ Email: Esteban M Rodríguez* - erodrigu@uach.cl \\ * Corresponding author
}

from 49th Annual Meeting of the Society for Research into Hydrocephalus and Spina Bifida

Barcelona, Spain, 29 June - 2 July 2005

Published: 30 December 2005

Cerebrospinal Fluid Research 2005, 2(Suppl I):S8 doi:I0.I I86/I743-8454-2-SI-S8

\section{Background}

In all species developing congenital hydrocephalus in which the SCO has been investigated, changes in the SCOReissner fibre (RF) complex have been reported. However, the question whether these changes precede hydrocephalus, or are a consequence of it, has not been fully clarified. We have reported that in the rat, the maternal transfer of antibodies against RF-glycoproteins to the foetuses and to the pups prevents RF formation and leads to aqueductal stenosis and hydrocephalus [1]. This finding gave support to the early hypothesis of Overholser et al. [2] who had proposed that a maldevelopment of the SCO may result in hydrocephalus. We have now designed new experimental protocols to further test this hypothesis.

\section{Materials and methods}

Since in the rat the first RF is formed around PN-7, we designed a protocol for the postnatal immunoneutralization of the SCO. Antibodies against RF-glycoproteins were perfused into the CSF at PN-2 and PN-5. At PN-30, $74 \%$ of these rats were devoid of $\mathrm{RF}$, had aqueductal stenosis and had developed hydrocephalus. A different strategy has been the study of the SCO in two mutant species developing congenital hydrocephalus, the hyh mouse and the HTx rat. During the first postnatal week the SCO of normal hyh mice forms the first Reissner fibre whereas that of the hydrocephalic littermates does not; the absence of RF preceded the obliteration of the Sylvius aqueduct and the development of a severe hydrocephalus. Similarly, the HTx rat lacks a RF despite having an active SCO. Since the absence of RF appears as a key event in the development of hydrocephalus, studies were performed to clar- ify the mechanism responsible for the lack of formation of RF.

\section{Results}

It was found (i) that the SCO of hyh mice has a decrease expression of SCO-spondin, the main constituent protein of RF; (ii) an alteration in the pattern of the secretory proteins present in the SCO, suggesting an abnormal processing or degradation. We have succeeded to detect and identify, for the first time, the SCO secretory proteins present in the CSF. It was found that the SCO of the hyh mice and the HTx rats secretes abnormal CSF-soluble proteins, and in the case of the HTx rats these proteins were more abundant. This is surprising since in the HTx rat only the supracommissural portion of the SCO develops; this implies that only about $20-30 \%$ of the secretory cells present in this mutant account for the increased quantity of secretory proteins present in the CSF. In the HTx there are SCO secretory products that are present in the ventricular CSF and missing from the subarachnoidal CSF. Thus, the CSF of both hydrocephalic species presents abnormalities in the quantity and quality of the SCO secretory proteins. Preliminary evidence indicates that CSF of children with congenital hydrocephalus contains secretory proteins which are missing from the CSF of nonhydrocephalic children.

\section{Conclusion}

1. A primary alteration in the SCO of the mutants hyh and HTx leads to: (i) a modification in the expression of its secretory proteins; (ii) an alteration in the processing of these proteins which, once released into the CSF, do not 
aggregate normally, resulting in the absence of RF and in the presence in the CSF of abnormal forms of such proteins. 2. The subarachnoidal CSF of HTx rats does not contain certain SCO secretory products. 3 . Detection in the human CSF of compounds that would correspond to SCO secretion may open a new field of research in human congenital hydrocephalus.

\section{Acknowledgements}

Supported by Grants from Fondecyt 1030265, Chile to EMR; and FIS, PI

030756 and Red CIEN C/0306, Instituto de Salud Carlos III, and Servicio

Andaluz de Salud, Spain to JMP-F.

Publish with Biomed Central and every scientist can read your work free of charge

"BioMed Central will be the most significant development for disseminating the results of biomedical research in our lifetime. " Sir Paul Nurse, Cancer Research UK

Your research papers will be:

- available free of charge to the entire biomedical community

- peer reviewed and published immediately upon acceptance

- cited in PubMed and archived on PubMed Central

- yours - you keep the copyright 